\title{
"O meu trabalho do dia a dia": o quotidiano das crianças na periferia de Maputo
}

\author{
"My daily work": day by day of children in the outskirts of Maputo
} "Mi trabajo del día a día": cotidiano de niños en la periferia de Maputo

ELENA COLONNA* \begin{abstract}
$\diamond$
\section{RESUMO}

$\mathrm{O}$ artigo apresenta os diferentes elementos que configuram o dia a dia das crianças de um bairro periférico da cidade de Maputo, discutindo-os a partir das contribuições da Sociologia da Infância e da Sociologia da Vida Quotidiana. Os dados apresentados permitem compreender e debater as formas como elas podem experimentar situações de exclusão social. Conclui-se que essas crianças vivem nesse contexto devido às suas condições materiais de existência e à relação fortemente hierárquica com os adultos. Contudo, elas conseguem experimentar e viver a inclusão social, sobretudo, dentro do grupo de pares.
\end{abstract}

Palavras-chave: Sociologia da Infância. Crianças. Quotidiano. Exclusão social. Moçambique.

\section{AbStract}

This paper presents the configuration of children everyday life in the suburbs of Maputo. Discussion is based on Sociology of Childhood and Sociology of Everyday Life contributions. Data allow understanding and debating the ways in which children can experience social exclusion. Conclusions point out that these children live in a context of social exclusion due to their material life conditions and to the strongly hierarchical relationship with adults. However, they are also able to experience social inclusion, especially within the peer group.

Keywords: Sociology of Childhood. Children. Everyday life. Social exclusion. Mozambique.

\section{RESUMEN}

El artículo presenta los diferentes elementos que configuran el día a día de los niños e de las niñas de un barrio periférico de la ciudad de Maputo, discutiéndolos a partir de las contribuciones de la Sociología de la Infancia y de la Sociología de la Vida Cotidiana. Los datos presentados permiten comprender y debatir las formas en que ellos pueden experimentar situaciones de exclusión social. Se concluye que estos niños viven en un contexto de exclusión social debido a sus condiciones materiales de existencia y a la relación fuertemente jerárquica con los adultos. Sin embargo, ellas logran experimentar y vivir la inclusión social, sobre todo, dentro del grupo de pares.

Palabras clave: Sociología de la Infancia. Niños. Quiropráctico. Exclusión social. Mozambique.

\footnotetext{
* Departamento de Sociologia-Universidade Eduardo Mondlane, Moçambique. <https://orcid.org/0000-0001-8217-8221>. E-mail:<elenamaputo@yahoo.it>.
} 


\section{INTRODUÇÃO}

"Hoje eu acordei com uma boa sorte e porque também terei umas boas aulas eu brinquei, trabalhei, estudei. Quando comecei a trabalhar, eu comecei com o meu trabalho de dia a dia este eu faço todos os dias varrer o quintal lavar os pratos fazer a limpeza todos os dias lá dentro na sala nos quartos, no corredor e na dispensa e na casa de banho e depois fui pôr água para poder regar os canteiros a relva e as plantas. Depois pus a água para poder tomar banho, quando acabei de tomar o banho, limpei-me e fui vestir. Almocei e despedi-me e fui a escola fui estudar muito bem." (Diário de Gilberto, 30-09-2008) ${ }^{1}$

Brincar, trabalhar, estudar. As palavras do Gilberto confirmam a ideia que foi sendo elaborada ao longo do trabalho de campo, junto das crianças de Infulene. ${ }^{2}$ Para além das atividades escolares (ir à escola, "ir à explicação" e fazer $\mathrm{TPC}^{3}$ ), que ocupam uma parte significativa do dia das crianças, o trabalho e a brincadeira parecem representar os dois eixos estruturantes dos quotidianos infantis no contexto estudado. Ainda uma rápida revisão da literatura permite confirmar que a centralidade dessas três categorias (a escola, o trabalho e a brincadeira) caracteriza a vida no dia a dia das crianças de grande parte do mundo. Contudo, a partir da perspectiva da Sociologia da Vida Quotidiana, que propõe um olhar atento a ver o que se passa mesmo quando nada se passa (PAIS, 2002), é possível compreender que há muito mais do que isso no quotidiano das crianças.

Os pequenos gestos do dia a dia, como comer, tomar banho, cumprimentar as pessoas e muitos outros, são reveladores das específicas formas de ser, sentir e agir das crianças estudadas, que, por sua vez, emitem informações também acerca do mundo social mais amplo onde elas estão inseridas. A esse respeito, Davis e Hill (2006, p. 14) ressaltam:

A exclusão social [das crianças] toma várias formas, algumas das quais estão enraizadas nas condições materiais das famílias e nas condições econômicas da sociedade, mas outras estão relacionadas com as relações sociais, sejam intergeracionais ou intrageracionais. Uma forma de exclusão social corresponde aos modos como as crianças pobres são marginalizadas por falta de recursos materiais. Outra reporta-se aos modos pelos quais as crianças são excluídas das principais decisões, dentro ou fora dos contextos familiares, de tal modo que as suas preferências e desejos não são reconhecidos pelos adultos.

\footnotetext{
${ }_{12}$ Foi respeitada a grafia dos registros nos diários das crianças.

2 Os dados apresentados neste artigo são o resultado da investigação etnográfica desenvolvida pela autora no bairro Infulene, entre agosto de 2008 e janeiro de 2010, no âmbito do seu doutoramento em Sociologia da Infância.

3 TPC: "trabalho para casa"; tarefas que os professores atribuem às crianças para serem desenvolvidas em casa.
}

Neste artigo, procura-se mostrar os diferentes elementos que configuram o dia a dia das crianças de um bairro periférico da cidade de Maputo, discutindo-os a partir das contribuições da Sociologia da Infância e da Sociologia da Vida Quotidiana. Os dados apresentados oferecem uma base para compreender e debater as formas como essas crianças podem experimentar situações de exclusão social.

\section{O ESTUDO DOS QUOTIDIANOS INFANTIS NA PERIFERIA DE MAPUTO}

\begin{abstract}
"8:00 Acordei. Estou em casa com a minha querida mãe e o meu irmão.

8:10 Fui diretamente ao banheiro lavar os dentes, depois de lavar os meus dentes voltei ao quarto para arrumar e varrer logo depois lavei a loiça acabei, às 10:30 fui ao mercado comprar as coisas necessárias para o matabicho ${ }^{4}$, esperei alguns minutos jogando a minha bola 11:00 mata-bichei acabei as 11:30 depois fui a escola ainda não tinha tocado o sino aproveitei o tempo para rever a matéria que estudamos depois o sino tocou eu e os meus colegas fomos à formatura mais uma vez cantamos o hino depois fomos a sala diretamente. Depois de acabarem as aulas fui para casa. Tomei um banho depois almocei, acabei, fui fazer o TPC acabei assisti a novela e o jornal, a minha mãe mandou-me pôr os pratos na mesa para o jantar jantamos a família toda depois de acabar de jantar despedi o meu pai e a minha mãe depois fui dormir." (Diário de Renato, 29-09-2008)
\end{abstract}

Para começar a apresentar o dia a dia das crianças de um bairro periférico da cidade de Maputo, optou-se por essa página do diário de Renato. A escolha não foi fácil porque, apesar de as atividades que constituem os quotidianos infantis serem aproximadamente as mesmas, cada criança escreveu o seu diário dando mais relevância a alguns aspetos e negligenciando outros. Contudo, esse relato pareceu-me condensar grande parte dos elementos que compõem o dia a dia das crianças e que representam o foco deste estudo: a higiene pessoal, o trabalho doméstico, as saídas para recados, a brincadeira, a alimentação (falta a preparação para a escola), a escola, os trabalhos escolares, a televisão, a relação com os adultos (na sua específica dimensão de "ser mandados"), as saudações e despedidas, o descanso.

Os diários das crianças são escritos com estilos diferentes, mais ou menos detalhados, sérios, irônicos ou íntimos, mas todos partilham a mesma apreensão da rotina da vida diária como uma realidade ordenada. De acordo com Berger e Luckmann (1999), os fenômenos do quotidiano encontram-se dispostos em padrões que

\footnotetext{
${ }^{4}$ Mata-bichar: pequeno almoço.
} 
parecem ser independentes da apreensão que deles é feita e à qual se impõem. Essa realidade "[...] aparece já objetivada, isto é, constituída por uma ordem de objetos que já tinham sido designados como objetos antes da minha entrada em cena" (BERGER; LUCKMANN, 1999, p. 33). É como se as crianças acordassem e encontrassem aí, à sua espera, uma série ordenada de tarefas por cumprir.

As tarefas que esperam quotidianamente as crianças, marcadas por um elevado grau de familiaridade, estão essencialmente associadas à atitude quotidiana (ou pensamento quotidiano). Essa atitude, objeto de estudo privilegiado da sociologia fenomenológica, coincide com a tendência a assumir a realidade como não problemática, sobretudo os aspectos que são pragmaticamente relevantes para as condutas quotidianas. Por outras palavras, coloca-se "entre parênteses" a dúvida de que as coisas possam ser pensadas ou realizadas de modo diferente de como se aprendeu a pensá-las e realizá-las (JEDLOWSKI, 2003).

Em nível prático, essa atitude corresponde à formação de hábitos e rotinas; em nível cognitivo, corresponde ao senso comum. As crianças, por meio de atitudes quotidianas, apreendem o mundo onde estão inseridas como familiar. Se a mãe manda Renato fazer compras, ele sabe como, ao chegar no mercado, pedir o que precisa, utilizar o dinheiro para pagar e voltar para a casa, sem precisar pensar muito. $\mathrm{O}$ sentimento de familiaridade que as crianças vivenciam possui um valor prático, uma vez que elas conhecem o seu contexto de vida e sabem como se comportar nele, mas também um valor psicológico. As crianças sentem-se seguras e à vontade no seu mundo, porque conhecem as pessoas, as ações, os espaços e os tempos que o compõem e sabem que todos os elementos estão organizados segundo uma certa ordem: "Eu de manhã acordo faço os trabalhos de casa depois faço o matabicho depois brinco também tenho um tempo de estudar fazer trabalho da escola" (Diário de Josefina, 29-09-2008).

Esse processo de "domesticação" da realidade, "[...] a crença que a maioria dos seres humanos têm na continuidade da sua auto-identidade e na constância dos ambientes sociais e materiais de ação em que estão inseridas", é o que Giddens (1990. p. 92) chama de segurança ontológica. Segundo o autor, segurança ontológica e rotinas estão intimamente ligadas. Também Pinto (1995) sugere que as rotinas constituem dimensões fundamentais da vida do dia a dia pelo fato de intervirem de forma significativa na estruturação temporal e espacial do quotidiano, assegurando que tempos, espaços e interações não se convertam numa experiência caótica e ameaçadora. Contudo, Coutinho (2010) aponta para a necessidade de problematizar a questão da repetição espácio-temporal, considerando também os possíveis aspectos negativos relacionados a uma excessiva rotinização dos quotidianos infantis:

\begin{abstract}
"Sempre em casa estou, sempre estou com a mesma pessoa, sempre a fazer a mesma coisa, o mesmo trabalho sabiam isso me cansa. Ter que ir a escola, estudar, ficar três tempos na sala sem sair isso me irrita e cansa, sabem eu gostaria de ser um mutante da liga do bem mas é lógico porque eu sou do mau mas estou no bem.” (Diário do Helder, 02-10-2008)
\end{abstract}

Nesse caso, Helder opta por fugir da repetição, ${ }^{5}$ princípio que marca de forma decisiva o dia a dia (GIDDENS, 1990), transformando-se num "mutante", uma personagem da novela a que ele costuma assistir. Com efeito, por meio da "fantasia do real", as crianças são capazes de reconstruir criativamente o real pelo imaginário, importando situações e personagens fantásticas para o seu dia a dia (SARMENTO, 2004). A seguir, analisam-se, de forma mais detalhada, as rotinas diárias que, em alguns casos (como o do Helder), podem cansar as crianças, mas na maioria das vezes as fazem se sentirem seguras, úteis e competentes.

\section{AS ROTINAS DAS CRIANÇAS}

O "dia" é a unidade de tempo escolhida para dar conta das rotinas das crianças. ${ }^{6}$ É concebido como uma sucessão de eventos dos quais participam não apenas as crianças estudadas, mas também outros atores, adultos e crianças, que com elas estão envolvidos nas diferentes situações do quotidiano (BONDIOLI, 2004). Durante o dia, obviamente, mudam os cenários, as figuras que cercam as crianças, o tipo de situação e as atividades desempenhadas. Os economistas Rodgers e Standing (1981) produziram um conjunto de categorias interculturais para definir as atividades das crianças: trabalho doméstico (limpar, cozinhar, tomar conta de crianças...); trabalho não doméstico e não retribuído (que se desenvolve no âmbito familiar); trabalho retribuído; atividades econômicas marginais (vender jornais, limpar sapatos, fazer recados...); escolarização, inatividade e desemprego, recreação e lazer, atividades reprodutivas (cuidados pessoais, alimentação e sono).

\footnotetext{
De acordo com Giddens (1990), a maioria dos trajectos espácio-temporais diários envolvem um "retorno", a partir do qual é possível considerar o tempo como reversível: o dia a dia transforma o tempo numa continuidade cíclica em que passado e futuro se indiferenciam. Essa ideia é criticada por Barbara Adam, segundo a qual nem o tempo nem os eventos se repetem. A repetição existe apenas de forma abstrata, criando a noção de hábito, isto é, tem-se consciência de que se está fazendo a mesma tarefa que se fez anteriormente, mas num tempo diferente (ADAM, 1990).

${ }^{6} \mathrm{O}$ dia corresponde ao período do ritmo circadiano das 24 horas, um biorritmo mínimo completo para a espécie humana, ao qual se acrescenta também a conotação social de dia útil ou feriado. O tempo diário é geralmente medido em relação à sua alocação nas diferentes atividades.
} 
Durante os dias da semana, grande parte do tempo das crianças estudadas é ocupada por trabalhos domésticos, escolarização e atividades reprodutivas. Para a maioria delas, recreação e lazer não costumam ter um tempo "dedicado", a não ser no fim de semana. A dimensão lúdica aparece sobretudo nos interstícios entre as outras atividades. Apesar das variações existentes entre as realidades das diferentes crianças, procura-se agora descrever um conjunto de ações que marcam o quotidiano de todas elas.

\section{Acordar}

Como é lógico, o dia de todas as crianças começa com o despertar. Apesar de as crianças envolvidas na investigação entrarem na escola às 12 horas, elas tendem a acordar entre 6 e 10 da manhã. A maioria acorda por volta das 7 horas. De modo geral, em Moçambique, e mais especificadamente no bairro estudado, a vida das famílias começa cedo por uma multiplicidade de fatores. A primeira razão é que amanhece cedo, entre 5 e 7 horas, mas também fica escuro cedo, às 18 horas no máximo. A entrada nas escolas e nos lugares de trabalho é usualmente marcada pelas 7 horas, e, considerando que a maioria das pessoas se movimenta a pé ou com o transporte público, é necessário sair de casa mais cedo para chegar a tempo.

Os trabalhos domésticos são muitos demorados e desenvolvidos principalmente ao ar livre, desde ir buscar água até cozinhar e lavar roupa, por isso é conveniente começar o mais cedo possível para conseguir acabar, mas também para aproveitar as primeiras horas do dia que são mais frescas. Apenas no inverno, quando as manhãs são mais escuras e frias, as crianças, como todos, ficam com vontade de demorar debaixo das mantas: "Acordei as 6:42. O frio das 6:42 é pesado a pessoa fica com vontade de dormir mais tempo" (Diário de Helder, 0810-2008). Uma vez que a vida da família começa, as crianças dificilmente continuam a dormir, quer porque partilham a cama ou o quarto com outros familiares, quer porque elas também têm coisas a fazer: "Hoje eu acordei às 6.00 horas. E o meu dia começou de manhã, eu acordei por cima da cama com os meus irmãos, que são: Edson, Filipe, Elena. Eu quando acordei lavei a cara arrumei a cama e fui varrer o meu quintal quando acabei fui pôr água para(?) poder regar os canteiros" (Diário de Gilberto, 29-09-2008).

Na maioria dos casos, as crianças começam os seus diários apenas com a expressão "acordei", deixando entender que provavelmente acordaram sozinhas ou pelo seu "relógio biológico interno" ou por terem ouvido barulhos e movimentos externos. De acordo com Casa-Nova (2009), a prática de não acordar as crianças corresponde a uma forma de socialização familiar respeitosa dos seus ritmos biológicos, que implica uma não artificialização do despertar. Cada criança acorda no seu próprio ritmo (acordei), quando o seu organismo deixa de sentir necessidade de repouso. Apenas em raros casos, as crianças relatam ter sido acordadas por outros familiares para realizar algum trabalho:

\begin{abstract}
"Minha mãe me acordou às 6 para fazermos limpeza." (Diário de Tomé, 07-10-2008)

"Hoje acordei às 6:30, quando meu irmão me acordou para ir comprar leite, porque lá na barraca não tinha o leite.” (Diário de Sabina, 30-09-2008)
\end{abstract}

\section{Higiene pessoal}

Os momentos de higiene pessoal ocupam um tempo importante no quotidiano das crianças, repetindo-se várias vezes ao longo do dia. Quase todas elas começam os diários com a frase: "Acordei, lavei a cara e escovei os dentes". Muitas acrescentam também tomar banho e pentear o cabelo. Parece-me interessante notar que esse ritual da manhã é também descrito numa canção infantil bem conhecida pelas crianças desde pequenas: "Lava a cara de manhã cedo, lava os dentes com uma escova, penteia-se muito bem para bonita ficar!". Nos primeiros anos de vida, são os mais velhos, principalmente as mães, que dão um banho demorado às crianças de manhã e à noite. Mais tarde, os adultos limitam-se a "mandar" as crianças tomar banho. Finalmente, na faixa etária das crianças envolvidas na investigação (10-14 anos), essa prática já representa um hábito que elas desempenham autonomamente.

Para além de uma limpeza rápida ao acordar, as crianças costumam tomar um banho antes de ir para a escola e outro ao voltar das aulas ou antes de dormir. Não é raro que elas tomem banho três ou quatro vezes por dia, incentivadas por motivações de tipo ambiental, pessoal, sanitário e social. ${ }^{7}$ Em primeiro lugar, é preciso considerar que Moçambique é um país tropical, com dias tendencialmente quentes ao longo de todo o ano. Ainda, a maioria das ruas e dos quintais são de areia e a poeira levanta-se facilmente com um pouco de vento ou com a passagem de um carro. Desse modo, é fácil que as crianças transpirem, movimentando-se para trabalhar e brincar, ou que os seus pés, protegidos geralmente por simples chinelos, fiquem empoeirados.

\footnotetext{
"Ao chegar a casa cumprimento a minha mãe e vou tomar um banho porque não aguentava com aquele todo calor que tinha depois fui comer." (Diário de Jessuina, 02-10-2008)

"Quando deu 10 pus água a ferver depois levei para casa de banho, tomei de novo banho porque tinha transpirado muito.” (Diário de Marina, 04-10-2008)
}

\footnotetext{
7 Gottlieb (2004), em seu estudo dos Beng da Costa de Marfim, relaciona os dois banhos diários dos bebés a motivações espirituais, médicas, estéticas, sociológicas e econômicas.
} 
A partir dos ensinamentos familiares e escolares, as crianças também elaboram a noção de que a higiene é importante para a sua saúde. Uma prática particularmente adotada é lavar as mãos antes das refeições: "Chegamos lavamos as mãos e depois almoçamos" (Diário de Ilda, 06-10-2008). Apesar das condições nem sempre fáceis decorrentes da falta de água canalizada nas casas, nas famílias moçambicanas, assim como em alguns restaurantes, garante-se que os hóspedes possam lavar as mãos fazendo circular entre eles uma caneca de água morna, uma pequena bacia e uma toalha. Também escovar os dentes várias vezes por dia pode ser considerado uma atitude relacionada com a saúde: "Depois fui escovar os dentes para tirar o cheiro da comida depois fui dormir" (Diário de Samuel, 29-09-2008).

Mas o banho não é encarado pelas crianças apenas como uma norma higiênica ou como uma necessidade decorrente das condições ambientais, mas também como um momento de bem-estar pessoal, uma ocasião para relaxar e cuidar de si. Várias crianças relatam levar intervalos de tempos significativos no banho: "Durante uma hora fui tomar banho para relaxar e me arrumei fui para escola" (Diário de Bento, 03-10-2008). Provavelmente, o tempo indicado não se refere apenas a passar a água e o sabonete pelo corpo, mas a todo o ritual que o banho implica. Uma vez que poucas casas possuem água canalizada e provavelmente nenhuma conte com um sistema automático para o aquecimento da água, as pessoas, incluindo as crianças, costumam pôr a água na chaleira ou numa panela para ferver no lume e depois a colocam numa bacia, onde acrescentam água fria até conseguir a temperatura desejada. Esse trabalho não é necessário quando o tempo estiver muito quente: "Tomei uma ducha de água gelada e lavei o meu cabelo secou" (Diário de Victória, 05-10-2008).

Quando a água está pronta, as crianças vão para a casa de banho, que frequentemente se encontra fora da casa, numa construção separada. Aí utilizam com muita habilidade as mãos ou uma caneca própria ${ }^{8}$ para passar a água no corpo. Depois, elas se secam e se cobrem (geralmente, as meninas utilizam uma capulana, e os rapazes, uma toalha) para sair da casa de banho e passar para o quarto. Se tiverem algum produto para hidratar a pele, as crianças aplicam-no, depois vestemse e, finalmente, penteiam-se e tratam do cabelo. Esse ritual é assim resumido por Vânia: "Aqueci água de banho, enquanto a água aquecia eu ia engomando uniforme quando a água estava pronta fui tomar banho depois me apliquei a loção" (Diário de Vânia, 03-10-2008).

\footnotetext{
${ }^{8}$ Uma outra regra fundamental é nunca misturar o material da cozinha (bacias, canecas, copos) com o da casa de banho.
}

Finalmente, os cuidados de higiene das crianças desempenham um papel social importante, tanto para o indivíduo quanto para a sua família. Uma criança suja, despenteada ou malvestida é, em primeiro lugar, objeto de gozação e, eventualmente, de exclusão por parte dos pares. Várias vezes, assisti a situações em que um irmão acusava o outro de cheirar a "chulé" ou de não ter tomado bem o banho. Também, aos olhos dos adultos, sejam eles vizinhos, sejam professores, a sua apresentação é imputada às condições morais e materiais da sua família. Nos bairros urbanos de Maputo, a incapacidade de cuidar apropriadamente das crianças é considerada vergonhosa e associada à pobreza e ao desamparo (PAULO; ROSÁRIO; TVEDTEN, 2008).

A questão do cabelo mereceria uma atenção especial, uma vez que na África esse cuidado está associado a específicos códigos culturais e desempenha um papel central na apresentação de si (FOFANA, 2010). As meninas, nos diários, frequentemente relatam ter ido "trançar" durante longas horas (sobretudo no fim de semana) ou fazer tranças em outras familiares. Nas conversas com as amigas, as crianças analisam e comentam detalhadamente os seus penteados. Existe uma grande variedade de tipos de tranças, e cada uma possui um nome específico, que pode ser utilizado para identificar uma pessoa. Em várias ocasiões, as meninas tentaram explicar de quem estavam a falar, referindo-se ao cabelo, com expressões do tipo "aquela que trançou Peter" ou "aquela que trançou com missangas coloridas". As crianças com penteados que requerem a compra de mechas e missangas geralmente vêm de famílias com um nível econômico familiar mais elevado e, eventualmente, podem gerar sentimentos de inveja nas outras meninas.

Os rapazes não dispõem da mesma variedade de opções das meninas em termos de penteados, contudo eles também dispensam uma discreta atenção ao seu cabelo. Em Moçambique, nas escolas públicas, assim como em muitos lugares de trabalho, é geralmente proibido aos homens deixar o cabelo crescer. Assim, as possibilidades variam desde careca até poucos centímetros de cabelo, sendo também possíveis cortes diferentes da juba. ${ }^{9}$ Nos diários, vários rapazes relatam ter ido cortar o cabelo, indicando que cuidar do cabelo é uma prática frequente não apenas para as meninas. A esse propósito, uma última nota interessante: na escola, em cada turma, existe um "chefe da higiene", encarregado de parar na porta da sala e controlar que todos os colegas que entram tenham o uniforme em ordem e o cabelo penteado. Caso não esteja, há sempre alguém com um pente à mão para resolver a situação.

\footnotetext{
${ }^{9}$ Com a expressão $j u b a$, as pessoas costumam referir-se à parte frontal da cabeleira que, nos homens, é cortada configurando desenhos diferentes.
} 
Cada cultura "molda a humanidade", não apenas em relação aos aspectos intelectuais, emotivos e éticos, mas também higiénicos e estéticos, que implicam dar forma e "cuidar" de corpos individuais (REMOTTI, 2000). De acordo com Gottlieb (2004), por meio de rituais de banho demorados e cuidadosos desempenhados pelas mães, os bebés experienciam o seu corpo como algo que merece uma grande dose de atenção. Talvez essa experiência dos primeiros anos de vida constitua mais um fator capaz de explicar os intensos cuidados que as crianças estudadas dedicam ao seu corpo.

\section{Cumprimentar e despedir}

Ao acordar, as crianças cumprimentam os familiares que estiverem em casa. Também os cumprimentam quando voltam para a casa depois de ter saído, assim como se despedem quando saem de casa e quando vão dormir. Cumprimentar e despedir-se das pessoas ao encontrá-las e deixá-las é uma prática comum na maioria das culturas do mundo. Contudo, o fato de a maioria das crianças registar essa ação no diário revela o grande valor que é atribuído às saudações no contexto estudado. Algumas crianças limitam-se a escrever que saudaram a família ou todos, enquanto outras detalham a lista de todos os familiares presentes que foram cumprimentados: "E fui dormir quando eu fui dormir primeiro fui dar uma boa noite à minha avó e à minha irmã e fui dormir" (Diário de Edson, 30-09-2008).

As expressões mais utilizadas são: cumprimentar, despedir, desejar bom dia ou boa noite e dar beijo ou beijinhos. Contudo, no âmbito da tradição moçambicana, as saudações implicam um ritual bem mais complexo do que um simples "olá", incluindo uma série de perguntas do interlocutor (como está de saúde, se descansou e/ou acordou bem, quando voltará...). As crianças, com a sua criatividade, podem também acrescentar novas questões para além daqueles rituais. Por exemplo, Neyma, todas as manhãs, cumprimenta o sobrinho de 3 anos, perguntando-lhe se dormiu bem e com quem sonhou. O menino, que provavelmente não se lembra, todos os dias inventa uma resposta, indicando as tias que estiverem por perto. No dia em que eu estava lá, durante esse ritual, ele respondeu que tinha sonhado comigo.

Algumas crianças registam de forma detalhada os diálogos que costumam ter com os seus familiares em diferentes ocasiões. Ao acordar, pais e filhos cumprimentam-se: "Disse a minha mãe bom dia mãe e ela disse bom dia filho" (Diário de Ornelas, 30-09-2008). Ao sair de casa, os filhos despedem-se dos pais e estes, por sua vez, dão-lhes a sua bênção: "Despedi da minha mãe eu disse mãe eu já estou a ir para a escola e ela disse está bem minha filha querida vai com Deus" (Diário de Célia,
03-10-2008). Ao visitarem os familiares, as crianças os cumprimentam e despedem-se:

"Fui ao Xipamanine com a minha tia ir fazer uma visita a minha bisavó chegamos lá cumprimentamos boa tarde avó como está de saúde? A minha avó disse eu estou bem." (Diário de Lalesca, 03-10-2008)

"Depois despedi a minha tia eu disse adeus tia já vou para casa a minha tia disse já vais minha sobrinha eu disse - Sim já vou a minha tia disse até quando eu disse até no sábado eu hei de vir passar o fim de semana." (Diário de Lalesca, 01-10-2008)

Finalmente, antes de dormir, as crianças desejam uma boa noite aos seus familiares e estes correspondem: "Despedi o meu tio e a minha tia, a minha prima e o meu primo". Eu disse: "Já vou dormir, até amanhã boa noite, bons sonhos". O meu tio disse: "Boa noite Neusia até amanhã". A minha tia também disse: "Boa noite Neusia, bons sonhos até amanhã". E eu disse: "Obrigada até amanhã" (Diário de Neusia, 30-09-2008).

A riqueza dos diálogos relatados pelas crianças permite compreender que cumprimentar e se despedir dos familiares não é apenas uma formalidade, mas constitui uma prática relevante do seu quotidiano. Esse hábito confirma e fortalece as relações sociais, esclarece as posições recíprocas e expressa aos outros respeito, interesse e afeto.

\section{Assistir à televisão, escutar música e jogar game}

Hoje, os meios de comunicação são uma parte imprescindível da vida quotidiana de cada um de nós. Assim, uma sociologia da vida quotidiana que não os considerasse seria mutilada de modo irremediável (SILVERSTONE, 1994). Isso vale também para as crianças de Infulene. Escutar músicas e jogar game g $^{10}$ são atividades essencialmente masculinas, relatadas nos diários e comentadas com os colegas na escola por um discreto número de crianças, porém nunca se teve a oportunidade de observar diretamente essas práticas. Por outro lado, a televisão está presente no quotidiano da totalidade das crianças. A maioria delas tem acesso a esse meio na sua casa, enquanto as outras têm de se deslocar para a casa dos vizinhos para poder assistir. Em casa da Márcia, teve-se a oportunidade de observar o ritual dos desenhos animados durante vários dias:

"Entro na sala. As pessoas são as mesmas de ontem: Márcia, Nilza e Nina. E, como ontem, a TV está ligada no Tom \& Jerry. Só a posição no espaço hoje é

\footnotetext{
${ }^{10}$ Game: expressão utilizada para indicar os videojogos. O português falado em Maputo inclui muitas expressões derivadas do inglês, devido à proximidade e aos contatos com a África do Sul.
} 
diferente. Em vez de deitadas na esteira, estão sentadas nas cadeiras. Márcia na mesa, com o livro e o caderno aberto, e as outras duas viradas para a TV. Márcia tira a pasta de uma cadeira para eu me poder sentar. Nina e Nilza nem me cumprimentam, nem tem qualquer tipo de reacção à minha presença, mas continuam a olhar para os desenhos animados. A situação continua assim até acabar o Tom \& Jerry: Márcia estuda e nós as três assistimos, menos algum olhar furtivo que troco com a Nina. Quando os desenhos acabam, assim como ontem, a Nilza levanta-se e vai embora. Hoje nem diz tchau, mas faz apenas um sinal com a mão para a Nina. Pergunto à Márcia se a Nilza vem assistir Tom \& Jerry todos os dias e ela diz-me que sim, mostra-me a casa dela logo do outro lado da rua." (Diário de Campo, 06-05-2009)

Os momentos dedicados a essa atividade são essencialmente dois: de manhã e à noite. De manhã, passam os desenhos animados, entre os quais o Tom e Jerry, acompanhados sobretudo pelas crianças que estão mais livres dos trabalhos domésticos: "Acordei bem disposto para tomar um banho e fui assistir bonecos animados de Tom and Jerry" (Diário de Edmilson, 29-09-2008). As crianças mais ocupadas às vezes conseguem assistir enquanto trabalham, mata-bicham ou fazem TPC, como no caso da Márcia, acima referido. O momento da noite é partilhado pela quase totalidade das crianças que referem assistir ao telejornal e sobretudo à novela, como última atividade antes de dormir: "Depois jantei quando acabei assisti a novela com o título Os Mutantes e depois fui dormir" (Diário de Anselmo, 08-10-2008).

A televisão ocupa um tempo limitado, mas relevante no quotidiano das crianças, porque lhes conta "[...] histórias, faz apelos à sua fantasia e imaginação, mostra-lhes acontecimentos, pessoas e lugares a que dificilmente teriam acesso de outro modo, permitindo-lhes viajar no tempo e no espaço" (PEREIRA, 2008, p. 222). Contudo, diversamente do que acontece no mundo minoritário, esse momento raramente é solitário. Na maioria das vezes é partilhado com os pares e/ou com os adultos. No seguinte episódio, Samito negocia com o irmão o uso da televisão, demonstrando não considerar assistir à TV como uma atividade que se faz passivamente, mas como uma atividade que requer competências específicas:

"Chego na sala e o Samito e o Valter estão sentados no sofá em frente da televisão, que está desligada. Pergunto se, por acaso, foi embora a energia. Samito responde: 'Não, é que já não há mais nada para assistir'. O irmão Valter não concorda e levanta-se para voltar a ligar a TV: 'Não, vamos ligar'. Samito insiste: 'Só há jogo. Sabe assistir jogo você?' 'Não', admite o Valter, mas liga na mesma a TV. Assiste um pouco, mas já que não há nada que lhe interesse, vai mudando a toda a hora de canal. Samito, então, levanta um pé para que ele não consiga mudar com o controlo remoto. Valter diz para tirar o pé, mas Samito responde que está a toda a hora a mudar e não está a assistir nada. Tem de desligar, porque assim só está a gastar energia. O Valter vai desligar." (Diário de Campo, 12-03-2009)

Essa situação apresentada confirma a pertinência do debate atual sobre crianças e TV, que propõe focalizar a atenção desde os efeitos da televisão nas crianças à audiência ativa exercida por elas. Contudo, de acordo com Buckingham (2009), o balanço entre "poder do texto" e "poder da audiência" não é algo que possa ser feito em abstrato. As complexas relações entre crianças e televisão só poderão ser adequadamente entendidas no âmbito de análises mais aprofundadas, que tenham em conta as formas em que esses elementos são construídos e definidos dentro de contextos sociais e culturais específicos (BUCKINGHAM, 2009).

\section{Trabalhos domésticos}

“As crianças trabalham - e também porque trabalham - são atores sociais plenos" (SARMENTO; BANDEIRA e DORES, 2005, p. 43). No âmbito da investigação, as contribuições das crianças à vida familiar resultam em ocupar a maior parte do seu tempo fora da escola. As crianças desempenham atividades para si (arrumar a sua cama e o seu quarto, preparar o seu mata-bicho, lavar o seu uniforme escolar...), mas, frequentemente, também lavam a louça e as roupas para os irmãos mais novos e para toda a família. O envolvimento das crianças nas tarefas domésticas começa logo ao acordar e, às vezes, só acaba depois que lavam a louça do jantar, antes de dormir. $\mathrm{O}$ trabalho doméstico inclui tanto atividades dentro de casa e no quintal (limpezas, lavar a louça, cozinhar) como outras que implicam sair (ir buscar água, fazer compras, pastar os cabritos).

Ao ler a maioria dos diários, tem-se a impressão de que as crianças já conhecem os seus trabalhos e os fazem autonomamente, sem instruções dos adultos: "Quando acordei lavei a cara arrumei a minha esteira, varri o meu quarto e a sala de casa, limpei as estufas mas também revi a matéria de Matemática, Português e outras" (Diário de Tomé, 30-09-2008). Contudo, alguns diários, e sobretudo as observações, indicam que o "ser mandados" representa um elemento constante nos seus quotidianos: "Quando eu acordei fui ter com a minha avó ela disse-me o que eu era para fazer e eu fui. $\mathrm{O}$ que ela disse-me quando eu acabei de fazer fui fazer TPC" (Diário de Edson, 01-10-2008). A mãe do Samito diz-lhe várias vezes para lavar a louça, mas ele está demasiado ocupado com a minha máquina fotográfica. 


\section{Brincar e outros divertimentos}

Brincar é geralmente considerada a atividade das crianças por excelência. Converteu-se "[...] numa espécie de arquétipo da atividade das crianças, na característica mais saliente do seu mundo de vida e no seu maior emblema" (FERREIRA, 2004, p. 82). Em oposição a essa ideia, o estudo dos quotidianos infantis no Infulene torna visível que o "ofício das crianças" não é apenas brincar. Os trabalhos domésticos e a escola ocupam a maior parte do seu tempo. Contudo, as crianças arranjam tempos e espaços para brincar: brincam ao trabalhar, brincam ao caminhar para algum lugar, brincam com os colegas da escola e com os irmãos, brincam sentadas no sofá, assim como a correr pelas ruas do bairro. A análise das brincadeiras das crianças nas suas múltiplas e variadas formas mereceria uma inteira tese de doutoramento, de modo que aqui não se oferece uma visão completa do fenômeno, mas tenta-se apenas dar uma ideia do lugar que a brincadeira ocupa no quotidiano das crianças.

Os momentos do dia em que as crianças geralmente dedicam à brincadeira ou a outros divertimentos são o fim da manhã (depois dos trabalhos domésticos e antes da preparação para a escola), os tempos livres na escola (a entrada, o intervalo e a saída) e o fim da tarde (depois de voltar da escola, tirar o uniforme e comer). Durante o fim de semana, as crianças costumam ter mais tempo livre de outras ocupações, e as brincadeiras não são limitadas a momentos específicos do dia. Pelo contrário, nos dias da semana, as brincadeiras tendem a se restringirem aos interstícios temporais, entre as responsabilidades domésticas e as atividades escolares: "Quando acabei de cozinhar fui chamar os meus irmãos para virem tomar chá. Acabei de tomar chá, fui para brincar. Mas eu não demorei muito porque eu devia fazer a preparação para $\mathrm{ACS}^{11}$ de English, Educação Cívica e Ciências Sociais" (Diário de Elídio, 01-10-2008).

As crianças brincam principalmente ao ar livre, no quintal de casa, nas ruas ou no pátio da escola. Nos diários, algumas vezes, elas escrevem simplesmente que foram brincar, enquanto outras vezes especificam com quem e do que brincaram. A companhia é geralmente representada por crianças do mesmo gênero quando se trata de amigos, enquanto o gênero pode variar no caso de crianças familiares (irmãos, primos, tios e sobrinhos). ${ }^{12}$ Entre os rapazes, a brincadeira mais frequente é jogar futebol. Quando alguma criança da vizinhança tem uma "verdadeira" bola de futebol, costuma ser chamada pelas outras para jogarem juntas ou para emprestar o precioso objeto. Caso não haja, jogam com uma bola feita por elas

\footnotetext{
${ }^{11}$ As ACSs (Avaliações Contínuas e Sistemáticas) são as provas escolares.

${ }^{12}$ Não é raro que nas famílias haja tios e sobrinhos quase da mesma idade.
}

mesmas com materiais reciclados. Também as balizas são realizadas com elementos que é possível encontrar no entorno, como pedras ou ramas de plantas. Outros desportos, como basquetebol e voleibol, são também praticados, mas com menos frequência, uma vez que requerem espaços e equipamentos específicos. Uma outra brincadeira muito comum entre os rapazes é jogar berlindes. Alguns meninos referem ir arrancar mangas nas árvores para comer e andar de bicicleta, um bem possuído por um exíguo número de crianças, mas geralmente partilhado com amigos e vizinhos.

Saltar corda, brincar no escorrega da escola e com bonecas são as brincadeiras referidas pelas meninas nos diários. Se não tiverem a corda, elas também sabem organizar-se com materiais reciclados, juntando entre eles uma série de pedaços de plástico. A observação participante permitiu conhecer uma variedade muito ampla de brincadeiras tradicionais praticadas pelas meninas: saltam dentro de quadrados desenhados no chão (neca), lançam um limão no ar e, antes de cair, têm de mexer umas pedrinhas (matokosana), cantam em círculo batendo entre elas as palmas das mão etc.

Tanto para as meninas como para os rapazes, os momentos de brincadeira são geralmente acompanhados pelas conversas com os amigos: "Fui brincar saltei corda conversei com as minhas amigas" (Diário de Aida, 08-10-2008) e "eu acabei de tomar chá e eu fui brincar com os meus amigos. Jogamos berlindes e muita conversa" (Diário de Elídio, 03-10-2008). Ir às festas e dançar representa um outro divertimento comum a todas as crianças, independentemente do gênero e da idade, que é partilhado também pelos adultos. Apesar de as festas serem uma atividade que caracteriza o fim de semana, as crianças não ficam à espera do sábado para dançar. Basta haver um pouco de música ou uns amigos que cantam e batem palmas para elas começarem a se mexer. Outras atividades que as crianças desempenham no tempo livre são ler e, mais raramente, escrever e desenhar, para além dos já referidos divertimentos ligados à tecnologia (assistir à TV, jogar game e escutar música).

É interessante notar que, em oposição ao estereótipo que define a brincadeira como a atividade das crianças por excelência, existem casos em que elas relatam estarem cansadas de brincar: "Nós saímos da sala, fomos para brincar. Eu me canso de brincar e fui para casa" (Diário de Elídio, 03-10-2008). Ainda, em várias oportunidades, constatou-se que as crianças se referiam ao brincar e às brincadeiras numa acepção negativa, sinônimo de algo que não é sério, em oposição ao trabalho e à escola que são considerados positivamente. "Brincar" impede de fazer bem outras atividades - "Fomos ensaiar o ensaio não foi um ensaio bom porque estavam a 
brincar" (Diário de Samuel, 29-09-2008) - e, sobretudo, de ter bons resultados na escola:

\begin{abstract}
"Eu pensei que estudava muito e no proveito não estudava muito mas chegou um dia que eu tomei uma decisão que queria estudar e na prova de inglês de 20 valores e de sociais tive 20 a minha mãe ficou com muita alegria e sorriu para mim me deu um presente porque eu tomei essa decisão e passei a não brincar não lanchar e fiquei muito feliz por decidir uma coisa bonita." (Diário de Dirce, 13-11-2008)
\end{abstract}

Esse foi apenas um panorama sobre as brincadeiras das crianças num bairro periférico da cidade de Maputo. Contudo, uma documentação cuidadosa e uma análise detalhada dos momentos de brincadeira das crianças podem permitir explorar empiricamente o complexo processo social, dentro do qual as crianças reorganizam ativamente as suas culturas de pares presentes e também as suas vidas futuras (EVALDSSON, 2009).

\section{Alimentação e digestão}

A alimentação, como uma das dimensões essenciais do ciclo da vida humana, está presente e representa um elemento importante nas rotinas diárias das crianças. Considerando que as que participaram da investigação estão em casa de manhã, saem para a escola por volta das $11 \mathrm{~h} 30 \mathrm{~min}$ e voltam depois das $17 \mathrm{~h} 30 \mathrm{~min}$, não admira que os seus horários das refeições se diferenciem do horário do resto dos familiares. Em termos gerais, as crianças mata-bicham por volta das $10 \mathrm{~h}$, depois de ter trabalhado e antes de preparar-se para a escola. Nessa primeira refeição, elas costumam tomar chá e comer pão com alguma coisa, frequentemente manteiga ou badja, ${ }^{13}$ às vezes, salada ou ovos: "Sentamos na mesa eu, Neyma, mana Arlete e Tady. Há um prato com pão, a tigela da manteiga, folha de chá Five Roses de Limão, o thermos com água quente e o açúcar" (Diário de Campo, 13-042009).

Depois, as crianças fazem um pequeno lanche durante o intervalo das aulas, por volta das $14 \mathrm{~h}$. Pode levar de casa uma sande e/ou um sumo, ou podem comprar bolachas, gelinhos e pipocas na escola. Ao chegarem em casa, as crianças costumam almoçar com um prato de comida constituído por arroz ou xima ${ }^{14}$ e carril: "Depois fui cozinhar arroz, fiz um pouco de carril de carne de galinha" (Diário de Maria, 07-10-2008). O carril é geralmente representado por verduras (couve, folha de abóbora, folha

\footnotetext{
${ }^{13}$ Badja: croquetes de feijão, que se comem geralmente dentro do pão (pão com badja). São preparadas e fritas por algumas mulheres nas suas casas e depois vendidas nas próprias casas ou nas esquinas das ruas por elas mesmas ou pelas crianças.

${ }^{14}$ Xima: papa preparada com farinha de milho e água. Representa um elemento-base da alimentação moçambicana.
}

de feijão...), carne ou peixe, preparados com um molho de amendoim pilado e leite de coco. O feijão também é um alimento bastante consumido. Por volta das $19 \mathrm{~h}$, no jantar, que costuma ser a única refeição partilhada por toda a família, às vezes, consome-se a mesma comida do almoço e outras vezes uma diferente.

Apesar dessa tentativa de generalizar as rotinas alimentares das crianças, é importante lembrar que no campo foi encontrada uma grande variedade em relação às refeições tanto no número, nos horários, nas expressões para defini-las quanto em termos de alimentos consumidos. Algumas crianças (assim como os adultos), logo de manhã, costumam comer a comida que sobrou da noite anterior, para ter força para trabalhar e aguentar até a preparação do mata-bicho. Outras costumam sentir fome ao longo do dia, fora dos horários das refeições: as mais novas pedem aos irmãos mais velhos para lhes darem pão ou comida ou para comprar pipocas, enquanto as mais velhas, que já têm algum dinheiro, compram biscoitos, amendoim, gelinhos ou frutas nas inúmeras bancas que se encontram nas ruas.

As expressões utilizadas para definir as refeições variam. Muitas crianças, nos diários e nas conversas, costumam utilizar a expressão "tomei chá" para indicar as refeições mais leves (chá ou leite, acompanhados por pão e alguma coisa) e "comi comida" para as mais completas. Algumas crianças referem "mata-bichar" e outras "almoçar" antes de ir para a escola e também ao voltar. Muitas delas utilizam a expressão "lanchar" para o meio da manhã e o fim da tarde, enquanto outras crianças criam novas expressões, escrevendo, por exemplo, que, de manhã, comem o "pequeno jantar". Ainda é importante salientar que as crianças costumam ter um envolvimento ativo no demorado processo de preparação das refeições, desde cozinhar até pôr a mesa e servir a comida:

\footnotetext{
"Quando cheguei em casa entrei no quarto e troquei de uniforme e comi comida, acabei de comer comida eu fui acender o lume para começar a cozinhar. Eu comecei a cozinhar o arroz e acabei de cozinhar o arroz e eu levei as panelas para dentro e deixei arrefecer. Quando a comida arrefeceu eu comecei a servir comidas e comemos." (Diário de Elídio, 01-10-2008).
}

Um último aspecto que me chamou atenção foi a consciência que as crianças têm dos seus órgãos internos e dos processos que aí acontecem. Por um lado, algumas referem que precisam comer para não sentirem dores de estômago: "Comi alguma coisa para que o meu estômago não dói” (Diário de Josefina, 29-09-2008). Porém, o mais interessante é que a maioria das crianças, em seus diários, relata o momento da digestão que segue as refeições: 
"Fui matabichar fiz digestão às 10:43 fui tomar banho" (Diário de Leonel, 01-10-2008). Frequentemente, as crianças "fazem digestão" antes de ir tomar banho ou de ir dormir, o que me fez pensar que essa ideia poderia decorrer de uma indicação dos adultos, a fim de evitar que apanhem frio no banho ou se deitem logo após a refeição. Contudo, é engraçado notar a interpretação rigorosa que as crianças fazem dessa norma, relatando que dedicam um tempo para a digestão mesmo antes de ir fazer o TPC ou de assistir à televisão: "Comi lanche e fiz digestão e comecei a escrever o TPC" (Diário de Xavera, 29-09-2008).

\section{Preparação para a escola}

A preparação para a escola é uma rotina que se repete todos os dias úteis e que é descrita de forma mais ou menos detalhada nos diários das crianças. $\mathrm{Na}$ verdade, essa preparação não é uma atividade única, pois engloba uma serie de tarefas. As crianças lavam e engomam o seu uniforme, mata-bicham, põem a água a ferver para o banho, tomam banho, vestem o uniforme, calçam as sapatilhas, ${ }^{15}$ penteiam o cabelo, arrumam os livros, os cadernos e o lanche na pasta, despedem-se dos familiares e saem de casa para ir à escola. A seguir, apresentam-se as descrições de três crianças, narrando sua preparação para as aulas. Cada uma delas ilumina diferentes aspectos desse ritual:

"8:30 h Lavei o meu uniforme depois arrumei os meus livros, quando o meu uniforme secou engomei-o. 11:00 h fui tomar banho tomei chá depois fui a escola." (Diário de Rita, 30-9-2008)

"Fui para casa ir ver horas e era as 10:30 h preparei os livros na pasta e fui tomar banho e acabei de tomar banho usei a roupa penteei o cabelo e acabei de me preparar enquanto era 11.20 matabichei e fui para escola as 11:35." (Diário de Samuel, 29-9-2008)

"10:40 Estava a deitar água na chaleira pra tomar banho. 11:00 já estava a escovar os dentes, pentear cabelo, vestir e calçar sapatilhas. 11:30 já estava a despedir minha irmã e minha mãe depois fui a escola." (Diário de Félix, 29-9-2008)

\section{Escola, TPC e explicação}

A escola e os trabalhos a ela relacionados ocupam grande parte do dia a dia das crianças. As aulas começam oficialmente às $12 \mathrm{~h} 10 \mathrm{~min}$ e acabam às $17 \mathrm{~h} 15 \mathrm{~min}$, contudo as crianças têm de chegar à escola um pouco antes para a concentração (das $11 \mathrm{~h} 55 \mathrm{~min}$ às $12 \mathrm{~h} 5 \mathrm{~min}$ ), quando se canta o hino nacional e os professores ou a

\footnotetext{
${ }^{15}$ A maioria das crianças fica todo o dia de chinelos e utiliza os sapatos só para ir à escola. Contudo, há também crianças que vão para a escola de chinelos.
}

diretora da escola dão alguma mensagem ou comunicação aos alunos. Por vezes, alguns professores exigem que os alunos entreguem os trabalhos que mandaram antes das $12 \mathrm{~h}$, de modo que os que vivem longe da escola optam por ir mais cedo e ficar à espera das aulas, enquanto os outros vão e voltam para casa: "Hoje acordei às 6 horas saí para fora, lavei a cara, escovei os dentes tomei banho levei caneta provas de matemática fui para escola para entregar e de novo voltei para casa tomar banho e arrumei os livros e fui para escola" (Diário de Maurícia, 24-10-2008).

Antes de ir à escola, depois de voltar e no fim de semana, as crianças dedicam algum tempo ao estudo e a fazer os TPCs. Muitas também aproveitam esses momentos para ir à "explicação" - aulas particulares individuais ou em pequenos grupos lecionadas por jovens da zona que frequentam classes mais avançadas em relação às crianças. Apesar de a escola, aulas adicionais e TPCs ocuparem um tempo considerável no quotidiano das crianças, essas atividades geralmente são descritas de forma muito breve nos diários. As crianças costumam limitar-se a fazer a lista das disciplinas que tiveram, enquanto relatam com mais pormenores as brincadeiras, a formatura, as limpezas e o recreio. Mesmo nas conversas em que se teve oportunidade de acompanhar, as crianças comentam muito mais os comportamentos dos professores e dos colegas do que os conteúdos das aulas.

\section{Regresso da escola}

O que acontece depois das aulas é geralmente contado de forma muito mais resumida em relação à parte da manhã, com o relato de uma série de ações, cada uma descrita apenas com um verbo: "Quando voltei da escola tomei banho assisti a televisão jantei e às 21:00 fui dormir" (Diário de Joice, 01-10-2008). Com efeito, as crianças saem da escola depois das $17 \mathrm{~h}$. Em seguida, começa a anoitecer. O bairro fica escuro devido à escassa iluminação e já não é recomendável circular no espaço público. Ao chegarem à casa, a primeira coisa que as crianças fazem é tirar o uniforme escolar, às vezes tomam um outro banho e após vestem "roupa de casa".

Depois de comer qualquer coisa, se for necessário, as crianças ajudam em casa, mas o trabalho não costuma ser muito, como acontece de manhã: elas fecham as portas e as janelas da casa, ajudam as mães a recolher as bancas, cozinham e põem a mesa... Se não houver trabalho, elas ficam relaxadas, fazem um pouco de TPC, brincam com os irmãos e assistem à televisão. Como já referido, o jantar geralmente reúne a maioria dos membros da família e depois o dia se conclui em frente da televisão, assistindo ao telejornal e à novela. 


\section{Dormir, sonhar talvez ${ }^{16}$}

Aúltima atividade do dia, depois de assistir à televisão, despedir-se dos familiares e mudar de roupa, é ir dormir. Nos diários, as crianças não fornecem muita informação sobre o sono, e também nunca se teve oportunidade de observar diretamente esse momento. Contudo, algumas conversas com as crianças e os seus relatos referentes ao momento de acordar dão algumas indicações acerca do repouso noturno. As crianças costumam ir descansar depois das novelas, entre $20 \mathrm{~h} 30 \mathrm{~min}$ e $21 \mathrm{~h} 30 \mathrm{~min}$, porém dormem mais tarde se tiver alguma coisa interessante na televisão. Márcia conta-me que dorme sempre às $20 \mathrm{~h} 30 \mathrm{~min}$, mas, às terças-feiras, dorme às $23 \mathrm{~h}$ para assistir ao programa "Fique ligado", que começa às $22 \mathrm{~h}$. Gilberto também conta ter dormido mais tarde para assistir a um filme: "O meu dia de hoje começou às 7 e 35 minutos foi a hora que acordei porque dormi muito tarde dormi as 22 horas ou 23 horas e dormi muito tarde porque eu e os meus irmãos estávamos a assistir filmes" (Diário de Gilberto, 03-10-2008).

Raramente, as crianças têm um quarto individual, mas costumam partilhar o espaço e, muitas vezes, também a cama, o colchão ou a esteira com outras crianças da família. Quando as crianças ficam sem sono e, se ainda estiver muito escuro para sair e começar a trabalhar, elas ficam a ler, estudar ou assistir à televisão dentro de casa: "Acordei as 5:30 porque não estava com sono. Não estava com vontade de dormir. E liguei a televisão assisti músicas eu gosto de Beyonce, Shakira, Khiana, Lizha James. Desliguei a televisão as 6:45" (Diário de Bento, 05-10-2008).

Finalmente, às vezes, as crianças sonham, ou melhor, lembram-se dos sonhos. Viu-se, no princípio desta secção, que todas as manhãs Neyma cumprimenta o sobrinho e pergunta-lhe com quem sonhou. Também nos diários, algumas crianças contam os seus sonhos noturnos, responsáveis pela sua boa disposição ao acordar: "Eu hoje acordei muito feliz porque eu sonhei com a minha família e sonhei muita coisa bonita e acordei as 8:24 quando acordei." (Diário de Ben, 03-10-2008).

E assim começa um novo dia com todas as suas rotinas:

"Terça-feira. Estou em casa com os meus irmãos. As 7:37 acordei fiz a cama, lavei a cara e lavei os dentes e tomei banho fui regar a relva depois terminei de fazer o TPC e depois fui fazer limpeza dentro acabei preparei matabicho as 9:00 e fui tomar banho e sai da casa de banho as 9:30 matabichei as 9:40 e vesti o meu uniforme as 10:50 sai de casa as 11 e cheguei na escola

\footnotetext{
16 "Dormir, sonhar talvez": é uma frase do celebérrimo Hamlet de William Shakespeare.
}

as 11:15 horas e formei cantamos hino nacional e fui a sala de aulas. Nas terças sempre temos Português, Educação Moral e Cívica, Educação Visual, Ciências Naturais e Educação Musical. Saí da escola as 17 e trinta cheguei em casa as 17:52 quando cheguei tomei banho fiz TPC depois assisti e as 20:00 jantei e as 21 fui despedir-me dos meus irmãos porque os meus pais não estão cá em Maputo viajaram. E por último fui descansar." (Diário de Atalina, 30-09-2008)

\section{CONCLUSÕES}

Sociologia da Vida Quotidiana é um empreendimento dedicado à tarefa - necessariamente interminável - de tornar objeto de reflexão aquilo que os seres humanos realizam de forma amplamente irreflexa no seu agir quotidiano (JEDLOWSKI, 2003). No âmbito deste artigo, volta-se a atenção para as rotinas quotidianas das crianças de um bairro periférico da cidade de Maputo. Apesar de os "normais" modos de vida das crianças moçambicanas terem sido geralmente negligenciados pelas investigações, estes representam elementos-chave não apenas para se compreender a infância e o seu lugar na organização social, mas também para se conhecer melhor a sociedade no seu conjunto.

O dia a dia das crianças estudadas desenvolve-se nas encruzilhadas entre velhas e novas instâncias, tradições e mudanças. Se, por um lado, as crianças cozinham acendendo o lume com o carvão e pilando amendoim com o mesmo pilão de madeira utilizado pelas suas avós e bisavós; por outro, elas podem consumir a refeição assim preparada assistindo ao "Tom \& Jerry" na televisão. O envolvimento com as tradições das gerações anteriores permeia a vida quotidiana, muitas vezes sem as pessoas refletirem sobre o seu uso (ROGOFF et al., 2007). Ao mesmo tempo, as ideias globais acerca das crianças configuram os quotidianos infantis ao nível local (WELLS, 2009).

A participação das crianças na vida familiar é uma das mais importantes maneiras de se ensinar e de se aprender aquilo que é necessário saber no contexto estudado (NUNES, 1999). As crianças não se limitam a interiorizar as normas da sociedade para depois se comportarem de forma coerente com elas. Pelo contrário, elas contribuem ativamente para a vida social, cooperando com os adultos na aplicação de normas e valores (CORSARO, 2003). Envolvendo-se ativamente nas tarefas domésticas, assim como nas práticas de higiene pessoal e nas outras rotinas diárias, as crianças chegam a compreender o significado dessas praxes e, ao fazê-lo, contribuem para a reprodução social. No fundo, a participação é aqui apresentada como uma efetivação germinal e quotidiana de uma agência significativa. 
Uma vez que essa agência é sempre enredada nas relações sociais, um dos desafios é não considerar as crianças como cumprindo ordens e expectativas que lhes são impostas pelos adultos, mas compreender e respeitar as crianças como participantes, com os seus próprios direitos, que agem de forma independente (LIEBEL; SAADI, 2010). Investigar a organização da participação das crianças nas atividades rotineiras oferece uma forma de abordar a natureza dinâmica dos repertórios de práticas culturais, entendidas como formatos de (inter) ação com os quais os indivíduos têm experiência, mas que podem assumir, contrariar e transformar (ROGOFF et al., 2007).

No contexto estudado, as relações entre os adultos e as crianças estruturam-se de forma extremamente hierarquizada, e as expectativas culturais exigem delas um forte senso de responsabilidade e obrigação em relação à família. Contudo, dentro das restrições que limitam as suas opções, as crianças conseguem negociar margens significativas de autonomia na organização do seu quotidiano. Muitas das suas estratégias são facilitadas pelo seu elevado nível de mobilidade dentro da comunidade e pelo seu uso extensivo do tempo e do espaço fora da vigilância direta dos adultos. As múltiplas estratégias implementadas não devem ser entendidas apenas como formas de resistência ao poder dos adultos, mas como parte de um processo complexo por meio do qual as crianças afirmam a sua agência, criando tempo e espaço para si, apesar das limitações colocadas por uma variedade de fontes, incluindo os adultos, as outras crianças e os constrangimentos estruturais (PUNCH, 2001).

De acordo com James, Jenks e Prout (2002), é sobretudo dentro e através dos interstícios temporais e espaciais das estruturas sociais adultas que emergem as culturas das crianças. Elas trabalham e estudam "de verdade", contudo "[...] o componente lúdico está sempre presente, ainda que por vezes dissimulado pela responsabilidade que também é preciso assumir" (NUNES, 1999, p.159). A oportunidade de viver as atividades quotidianas na sua dimensão lúdica é, de certa forma, garantida pelo fato de as crianças estarem quase constantemente, em relação com os pares, tanto em casa como na escola e no espaço público.

Christensen e James (2005) sustentam que a experiência de ser criança varia através das culturas, mas também de forma sutil, dentro da mesma cultura. No grupo estudado, existem várias tipologias de crianças, que apresentam modalidades ligeiramente diversificadas de organizar e distribuir o tempo entre diferentes atividades, espaços e companhias. Contudo, há uma tipologia, cada vez mais difundida nos países europeus, que não foi encontrada no contexto analisado:
[...] crianças que não têm nem mesmo um espaço à disposição e nenhum companheiro de brincadeiras nas vizinhanças e que não dispõem de formas privadas de marcar encontros. Essas crianças, que também encontramos na nossa pesquisa, passam as suas tardes em parte sozinhas em casa, em parte compartilhando a vida dos seus pais, mas sem amigos da mesma idade (ZEIHER, 2004, p. 187).

Se, por um lado, pode-se considerar que as crianças aqui estudadas vivem num contexto de exclusão social devido às suas condições materiais de existência (às vezes, bastante precárias) e à relação fortemente hierárquica com os adultos; por outro lado, as intensas relações intrageracionais que elas estabelecem fazem com que experimentem e vivam a inclusão social dentro do grupo de pares. A interdependência negociada tanto com os pares como com os adultos, a agência, a autonomia no uso do tempo e a participação na vida familiar e comunitária são alguns aspectos que se considera como caracterizadores do quotidiano das crianças envolvidas nesta investigação. Contudo, segundo Pais (2002, p. 35), “[...] importa fazer da sociologia do quotidiano uma viagem e não um porto". Por isso, consciente de não se ter chegado a lado nenhum, considera-se que essas reflexões são apenas considerações provisórias acerca daquilo que se viu, ouviu e aprendeu ao longo do caminho. Sem dúvida, essas ideias podem ser aprofundadas ou reformuladas em futuros trabalhos por quem decidir sair à descoberta dos quotidianos das crianças moçambicanas após a leitura destas páginas.

\section{REFERÊNCIAS}

ADAM, Barbara. Time and social theory. London: Polity Press. 1990.

BERGER, Peter L.; LUCKMANN, Thomas. A construçao social da realidade. Lisboa: Dinalivro. 1999.

BONDIOLI, Anna. O dia-a-dia de Erika em casa e na escola: padrões de socialização em confronto. In: BONDIOLI, Anna (Org.). $O$ tempo no cotidiano infantil: perspectivas de pesquisa e estudos de caso. São Paulo: Cortez, 2004.

BUCKINGHAM, David. Children and television. In: QVORTRUP, Jens; CORSARO, William A.; HONIG, MichaelSebastian (Org.). The palgrave handbook of childhood studies. Hampshire: Palgrave Macmillan, 2009.

CASA-NOVA, Maria José. Etnografia e produção de conhecimento: reflexões críticas a partir de uma investigação com ciganos portugueses. Lisboa: Acidi, 2009.

DAVIS, John; HILL, Malcom. Participation for what: an introduction. In: TISDALL, Kay et al. Participation for what: children, young people and social inclusion. Bristol: Policy Press, 2006.

EVALDSSON, Ann-Carita. Play and games. In: QVORTRUP, Jens; CORSARO, William A.; HONIG, Michael-Sebastian (Org.). The palgrave handbook of childhood studies. Hampshire: Palgrave Macmillan, 2009. 
GIDDENS, Anthony. La costituzione della società. Milano: Comunità, 1990.

JEDLOWSKI, Paolo. Fogli nella valigia: sociologia, cultura, vita quotidiana. Bologna: Il Mulino, 2003.

LIEBEL, Manfred; SAADI, Iven. Participation in the traps of cultural diversity. In: PERCY-SMITH, Barry; THOMAS, Nigel. A handbook of children and young people's participation. Oxon: Routledge, 2010.

NUNES, Ângela. A sociedade das crianças a'uwe-xavante: por uma antropologia da criança. Lisboa: Instituto de Inovação Educacional, 1999.

PAIS, José Machado. Sociologia da vida quotidiana. Lisboa: Imprensa de Ciências Sociais, 2002.

PAULO, Margarida; ROSÁRIO, Carmeliza; TVEDTEN, Inge. "Xiculungo": relações sociais da pobreza urbana em Maputo, Moçambique. Maputo: Direcção Nacional de Estudos e Análise das Políticas - MPD, 2008.

PEREIRA, Sara. Crianças e televisão: convergências e divergências de um campo de estudos. In: SARMENTO, Manuel Jacinto; GOUVEA, Maria Cristina Soares. Estudos da infância. Petrópolis, RJ: Vozes, 2008.

PUNCH, Samantha. Negotiating autonomy: childhoods in rural Bolivia. In: ALANEN, Leena; MAYALL, Berry. Conceptualising child-adult relations. London: Routledge Falmer, 2001.

REMOTTI, Francesco. Prima lezione di antropologia. Bari: Laterza, 2000.
ROGOFF, Barbara et al. Children's development of cultural repertoires through participation in everyday routines and practices. In: GRUSEC, Joan E.; HASTINGS, Paul D. Handbook of socialization: theory and research. New York: Guilford Press, 2007.

SARMENTO, Manuel Jacinto. As culturas da infância nas encruzilhadas da segunda modernidade. In: SARMENTO, Manuel Jacinto; CERISARA, Ana Beatriz. Crianças em miúdos. Porto: Edições ASA, 2004.

SARMENTO, Manuel Jacinto; BANDEIRA, Alexandra; DORES, Raquel. Trabalho domiciliário infantil: um estudo de caso no Vale do Ave. Lisboa: PETI, 2005.

SILVERSTONE, Roger. Television and everyday life. London: Routledge, 1994.

WELLS, Karen. Childhood in a global perspective. Cambridge: Polity Press, 2009.

ZEIHER, Helga. O tempo no cotidiano das crianças. In: BONDIOLI, Anna. O tempo no cotidiano infantil: perspectivas de pesquisa e estudos de caso. São Paulo: Cortez, 2004.

Recebido em 27.04.2018

Aprovado em 04.07.2018

Endereço para correspondência:

Universidade Eduardo Mondlane

Faculdade de Letras e Ciências Sociais (FLCS)

Departamento de Sociologia

Av. Julius Nyerere, 3453 - Maputo

CP 257 - Maputo, Moçambique 